\title{
Patients' preferences for coronary revascularization: a systematic review
}

This article was published in the following Dove Medical Press journal: Patient Preference and Adherence

\section{Carlos Alberto da Silva Magliano' \\ Andrea Libório Monteiro ${ }^{2}$ Amanda Rebeca de Oliveira Rebelo' Claudia Cristina de Aguiar Pereira $^{3}$}

'Instituto Nacional de Cardiologia, INC, Rio de Janeiro, Brazil; ${ }^{2}$ Department of Pharmacy Systems, Outcomes and Policy, College of Pharmacy, University of Illinois at Chicago, Illinois, USA; ${ }^{3}$ Escola Nacional de Saúde Pública, ENSP, FIOCRUZ, Rio de Janeiro, Brazil

Correspondence: Carlos Alberto da Silva Magliano

Instituto Nacional de Cardiologia, INC, Rua das Laranjeiras $374,5^{\circ}$ andar, NATS, Rio de Janeiro CEP22240-006, Brazil Tel +5521996802076

Email carlosincnats@gmail.com
Aims: Current recommendations regarding the best treatment option for coronary revascularization are usually based on composite outcomes that were not selected or weighed with patients thence they may fail in representing patients' preferences adequately. This systematic review aimed to appraise existing literature surrounding stated preference (SP) regarding coronary revascularization.

Methods and results: Studies related to SP regarding coronary revascularization were searched on Medline, Embase and Lilacs databases. Two reviewers screened all titles independently, and consensus resolved any disagreements. Of 735 total citations, six studies were included and qualitatively synthesized. Notably, the attributes most often cited in these studies coincided with those already used in clinical trials (death, myocardial infarction, stroke and redo revascularization). Half of the studies analyzed the use of composite endpoints and showed the necessity to review this practice since the attributes are weighed differently, and there is a disagreement between patients and physicians. Also, a large variety of methods were used to elicitate and value the attributes such as rating, ranking, standard gamble, willingness to pay, and discrete choice experiments.

Conclusion: Despite a large number of studies comparing revascularization treatment efficacy, there are just a few focusing on patients' preferences. The selection of outcomes to be considered in the trade-off between treatment options and how to weigh them properly, taking into consideration patients' preferences, need to be explored in future trials.

Keywords: review, systematic, preference, patient, angioplasty, transluminal, percutaneous coronary, bypass surgery, coronary revascularization

\section{Introduction}

Coronary artery disease (CAD) is the leading cause of mortality worldwide. For patients with symptomatic CAD refractory to medical therapy, there are two revascularization options: percutaneous coronary intervention (PCI) and coronary artery bypass grafting $(\mathrm{CABG})$. The least invasive option is $\mathrm{PCI}$, as it does not require open-heart surgery. On the other hand, CABG is the gold standard approach for some patients, mainly for those with multivessel disease, diabetes, left main coronary disease or left ventricular dysfunction. ${ }^{1}$

While cardiologists and surgeons debate on the optimal revascularization method, little is known about the viewpoint of patients. Decision-making in illnesses with more than one viable treatment option may involve trade-offs that are valued differently by patients and physicians. Regarding CAD, to elicit patients' preferences may be particularly relevant for the $\sim 12 \%$ of patients needing coronary revascularization who are eligible for either PCI or CABG. ${ }^{2}$ Patients' preferences can be evaluated according to patient's choice among treatment options, reflecting the importance they place on each treatment attributes. ${ }^{3}$ 
There are two methods to measure preferences: 1 ) stated preference (SP) that elicits subjects' preferences for hypothetical options in an experimental framework and 2) revealed preferences (RP) that are based on individuals' actual behavior in real decision contexts. ${ }^{4}$ In healthcare, RP data are often unavailable or unfit to characterize patients' preferences, since the consumption of goods is not exclusively determined by their choices, being hard to determine who (patient, caregiver or physician) and why (preferences, patient's clinical characteristics, coronary disease anatomy or the availability of treatments) one option was chosen. In SP, which is experimental, it is possible to control the survey design and to estimate the trade-off between attributes considering the respondents' preferences. The application of SP techniques, such as discrete choice experiments, has become increasingly popular in outcome researches.

This systematic review aimed to identify SP studies that appraised the trade-off between PCI and CABG for CAD and to survey the attributes identified as important in the choice between treatments, how they were valued; the methods used to elicit preferences; possible differences between patients and physicians regarding the attributes' importance and to highlight potential areas for further exploration.

\section{Methods}

We performed a systematic review of published studies to investigate patient and physician preferences for PCI or CABG. Medline, Embase, and Lilacs databases were searched for studies published in or before 10 January 2017.

Our search terms consisted of keywords for coronary revascularization, as well as methods used to assess patient preferences (eg, "patient reported outcome," "patient satisfaction," "best-worst scaling," Maxdiff, "discrete choice experiment," preference, "conjoint studies," "conjoint choice experiment," vignette, choice, willingness-to-pay, and "conjoint analysis").

The detailed strategies are included in Table S1. A written study protocol was prepared following the PRISMA statement, ${ }^{5}$ and the review was registered in PROSPERO (systematic review record CRD42016048664) in September 2016.

\section{Study selection and data extraction}

Inclusion criteria were: SP studies regarding CAD treatments. Both patients and physicians' preferences were surveyed. There were no restrictions regarding language. Exclusion criteria: articles with no original data (eg, review, commentary, editorial, or meeting abstract).
Two reviewers (CM and $\mathrm{AL})$ screened all titles and summaries independently. Articles were excluded at this stage if both reviewers determined that they did not meet the inclusion criteria. Disagreements were resolved by consensus. The same two researchers then reviewed the full text of all remaining articles and extracted data, including information on study design, locations, sample size, participant characteristics, preference elicitation methods, funding sources, and treatment-related attributes associated with patient preferences.

\section{Data synthesis and analysis}

We decided a priori not to statistically combine results in a meta-analysis since we expected studies to be methodologically and clinically diverse. Therefore, the results were qualitatively synthesized. The points prioritized were: 1 ) primary objectives; 2 ) sample size; 3 ) preference elicitation methods; 4) sources of financing; 5) attributes evaluated; and 6) differences between physicians and patients' perspectives.

\section{Results}

\section{Study characteristics}

Of 735 total citations (436 from Medline, 299 from Embase), 44 articles were eligible for full-text review. We included six studies ${ }^{2,6-10}$ that met our inclusion criteria in the final report (Figure 1). Eligible studies were conducted from 1999 to 2015. All studies were cross-sectional, and sample sizes ranged from 53 to 616 participants. Four $(67 \%)$ studies were performed in the USA ${ }^{2,6,7,9}$ and two $(33 \%)$ in the UK. ${ }^{8,10}$ None of these studies were funded by pharmaceutical companies.

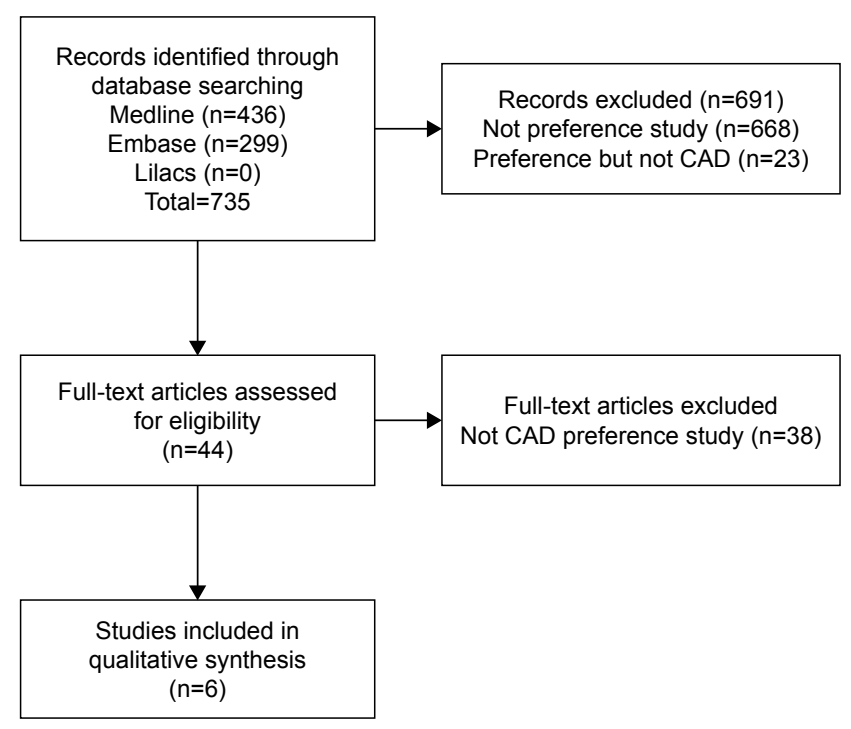

Figure I PRISMA flow chart of search strategy. Abbreviation: $C A D$, coronary artery disease. 


\section{Methods used to assess patient preferences}

Methods to evaluate patient preferences for revascularization included the following: rating, ${ }^{2,6-8,10}$ ranking, ${ }^{2,10}$ standard gamble, ${ }^{2}$ willingness to pay, ${ }^{2}$ conjoint analysis, ${ }^{2}$ and discrete choice experiments ${ }^{9}$ (Table 1).

\section{Attributes associated with patient treatment preferences}

The attributes most often cited in these studies coincided with those already used in clinical trials: death, ${ }^{6-9}$ stroke, ${ }^{6-9}$ myocardial infarction ${ }^{6,8}$ and repeat revascularization..$^{2,7-9}$ Other attributes examined within studies included: heart attack, ${ }^{7}$ hospitalization, ${ }^{7}$ repeat PCI, ${ }^{6}$ repeat $\mathrm{CABG},{ }^{6}$ atrial fibrillation, ${ }^{6}$ mediastinitis, ${ }^{6}$ postoperative chronic pain, ${ }^{2,6}$ postprocedural angina, ${ }^{6,7}$ length of stay, ${ }^{2,6}$ duration of recovery, ${ }^{2,6}$ depression, ${ }^{6}$ procedural cost ${ }^{6}{ }^{2}$ incision scar, ${ }^{2,6,10}$ pseudoaneurysm, ${ }^{6}$ pneumonia, ${ }^{6}$ long-term use of clopidogrel, ${ }^{6}$ renal failure, ${ }^{6}$ acute respiratory distress syndrome, ${ }^{6}$ bleeding, ${ }^{6}$ symptom control, ${ }^{10}$ medication side effects, ${ }^{10}$ comfort in taking medication, ${ }^{10}$ well-being, ${ }^{10}$ ability to do things, ${ }^{10}$ prolong life, ${ }^{10}$ and cure. ${ }^{10}$

\section{Main findings}

Death, stroke, myocardial infarction, and repeat revascularization are frequently grouped into a category called major adverse cardiovascular events (MACE). The use of MACE has been justified as an attempt to capture the overall treatment effect and it represents a possible way to reduce the duration, sample size and costs of a clinical trial. ${ }^{6,7}$ In this review, from the six studies that evaluated preferences between PCI and CABG, three focused on the utilization of composite endpoints. ${ }^{6-8}$

In the first one, Pandit et $\mathrm{al}^{6}$ recruited physicians by emailing and patients directly from a cardiac catheterization laboratory. They rated on a scale of $0-10$, the relative weight of each group placed on potential adverse outcomes

Table I Summary of evidence

\begin{tabular}{|c|c|c|c|c|}
\hline $\begin{array}{l}\text { Study and } \\
\text { country }\end{array}$ & Population & Objectives & Methods & Main results \\
\hline $\begin{array}{l}\text { Pandit et al } 2014^{6} \\
\text { USA }\end{array}$ & $\begin{array}{l}54 \text { patients, } \\
57 \text { physicians }\end{array}$ & $\begin{array}{l}\text { To assess the relative } \\
\text { weight each group } \\
\text { (patients and physicians) } \\
\text { places on potential adverse } \\
\text { outcomes from either } \mathrm{PCl} \\
\text { or CABG }\end{array}$ & $\begin{array}{l}\text { Rating outcomes on a scale } \\
\text { of } 0-10\end{array}$ & $\begin{array}{l}\text { Patients weighted stroke the } \\
\text { heaviest and repeat } \mathrm{PCI} 15 \text { out of } 20 \\
\text { outcomes. Physicians weighted death } \\
\text { as the heaviest }\end{array}$ \\
\hline $\begin{array}{l}\text { Chow et al } 2014^{7} \\
\text { USA }\end{array}$ & 100 patients & $\begin{array}{l}\text { To determine the } \\
\text { preferences of patients } \\
\text { regarding outcomes } \\
\text { included on the design } \\
\text { of cardiovascular trials }\end{array}$ & $\begin{array}{l}\text { Rating (heart attack, heart death, } \\
\text { death, chest pain-hospitalization, } \\
\text { repeat revascularization and } \\
\text { stroke) on a scale from I to } 6\end{array}$ & $\begin{array}{l}\text { Heart attack and death from heart } \\
\text { disease were the most important } \\
\text { endpoints to be included in a } \\
\text { cardiovascular trial. }\end{array}$ \\
\hline $\begin{array}{l}\text { Ahmad et al } 2015^{8} \\
\text { UK }\end{array}$ & $\begin{array}{l}\text { I I } 3 \text { patients, } \\
50 \text { cardiologists }\end{array}$ & $\begin{array}{l}\text { To determine the } \\
\text { preferences of patients } \\
\text { regarding outcomes } \\
\text { included on the design } \\
\text { of cardiovascular trials }\end{array}$ & $\begin{array}{l}\text { Visual analog scale. The relative } \\
\text { importance of myocardial } \\
\text { infarction, stroke, and repeat } \\
\text { revascularization indexed to the } \\
\text { death's value }\end{array}$ & $\begin{array}{l}\text { Patients considered stroke worse } \\
\text { than death. Patients valued outcomes } \\
\text { significantly different than physicians. }\end{array}$ \\
\hline $\begin{array}{l}\text { Hornberger et al } \\
1999^{2} \\
\text { USA }\end{array}$ & 304 respondents & $\begin{array}{l}\text { Determinants of clinical } \\
\text { decision-making in patients } \\
\text { with stable coronary artery } \\
\text { disease }\end{array}$ & $\begin{array}{l}\text { Conjoint analysis, ranking/rating, } \\
\text { standard gamble, and WTP. } \\
\text { Outcomes: scar, pain, recovery } \\
\text { time, days in hospital and repeat } \\
\text { revascularization }\end{array}$ & $\begin{array}{l}\text { Repeat revascularization was the } \\
\text { most important outcome ( } 28 \% \text { risk } \\
\text { rate threshold to change } \mathrm{PCl} / \mathrm{CABG} \text {.). }\end{array}$ \\
\hline $\begin{array}{l}\text { Kipp et al } 2013^{9} \\
\text { USA }\end{array}$ & $\begin{array}{l}585 \text { patients, } \\
31 \text { physicians }\end{array}$ & $\begin{array}{l}\text { Determinants of clinical } \\
\text { decision-making in patients } \\
\text { with stable coronary artery } \\
\text { disease }\end{array}$ & $\begin{array}{l}\text { Mixed effects logistic regression } \\
\text { analysis. Outcomes: death, stroke } \\
\text { and repeat revascularization }\end{array}$ & $\begin{array}{l}\text { Patients preferred } \mathrm{PCl} \text { over } \mathrm{CABG} \\
\text { more than physicians and even when } \\
\text { the risk of death was double, and the } \\
\text { risk of repeat procedures was more } \\
\text { than three times the CABG risks. }\end{array}$ \\
\hline $\begin{array}{l}\text { Bowling et al } 2008^{10} \\
\text { UK }\end{array}$ & 53 patients & $\begin{array}{l}\text { Preferences for angina } \\
\text { treatments among patients } \\
\text { admitted from emergency } \\
\text { with acute coronary } \\
\text { syndrome }\end{array}$ & $\begin{array}{l}\text { Rank/rating. Four treatment } \\
\text { options: } \mathrm{CABG}, \mathrm{PCl} \text {, drugs to } \\
\text { prevent symptoms or to prevent } \\
\text { symptoms and partly to reduce } \\
\text { the risks of a heart attack }\end{array}$ & $\begin{array}{l}\mathrm{PCl} \text { was the preferred treatment } \\
(80 \%) \text {, followed by CABG (19\%). }\end{array}$ \\
\hline
\end{tabular}

Abbreviations: $C A B G$, coronary artery bypass grafting; $\mathrm{PCl}$, percutaneous coronary intervention; WTP, willingness to pay. 
from either PCI or CABG. The outcomes selected were: stroke, death, peri-procedural myocardial infarction, acute respiratory distress syndrome, renal failure, repeat $\mathrm{CABG}$, repeat PCI, major bleed, atrial fibrillation, mediastinitis, postoperative chronic pain, postprocedural angina, long-term clopidogrel, pneumonia, length of stay, length of recovery, depression, procedural cost incision scar and pseudoaneurysm (Table 1). Patients weighted stroke the heaviest (8.83 out of 10), physicians weighted death the heaviest (8.63), and both groups considered the incision scar as the lightest. There was a statistically significant difference in weighting most outcomes between groups. Notably, patients weighted repeat percutaneous coronary revascularization, a common outcome in MACE, lower than most others (15 out of 20). Based on Pandit's survey, future studies of PCI vs CABG should report more than just MACE.

In the second study, ${ }^{7}$ patients from a primary care practice were asked about the use of single vs composite endpoints in cardiovascular trials and they also should score, on a scale of 1-6, the following outcomes: heart attack, death related to heart disease, death from other causes, stroke and hospitalization with chest pain. Participants expressed a preference for composite endpoints. The authors hypothesized that patients must have considered it easier to deal with one composite endpoint than to analyze many single endpoints. Importantly, participants did not value the endpoints as being equivalent, most of them indicated that death from heart disease (4.73), heart attack (4.53), death (3.69) and stroke (3.15) were the most relevant endpoints to be included in a trial.

Ahmad et $\mathrm{al}^{8}$ surveyed the relative importance of the components of MACE using a visual analog scale in hospitalized patients and cardiologists. Neither patients nor physicians considered all clinical endpoints equal. Stroke was found to be worse than death for patients and comparable for doctors. Interestingly, Ahmad et $\mathrm{al}^{8}$ reanalyzed a meta-analysis with seven randomized clinical trials which had compared CABG to PCI. When clinician-weighted event rate was used, CABG was found to be superior, but when the patient-weighted event rate was considered, there was no statistically significant difference.

Composite endpoint was identified as frequently used in clinical trials and even preferable by most patients, supposedly because it is easier to deal with one than to jointly analyze many single endpoints, but since the outcomes have different values, they should be analyzed considering the attributes' weights.

Hornberger et $\mathrm{al}^{2}$ used various techniques of preference assessment (rating, ranking, conjoint analysis, standard gamble, and willingness to pay) to evaluate the importance patients attach to the consequences of coronary revascularization. The outcomes evaluated, in order from the most to the least relevant were: "3-year risk of repeat revascularization," "50\% reduction in post procedure pain," "time spent in hospital," "6-week reduction in time needed to resume normal activities," and "body appearance (scar)." When the extent respondents preferred to avoid repeat revascularization with a standard gamble technique was assessed, they became indifferent between PCI and CABG when the risk of repeat PCI was reduced from $50 \%$ to $28 \%$ (95\% CI $25 \%-31 \%$ ). Bowling et $\mathrm{al}^{10}$ applied the Coronary Revascularization Outcome Questionnaire among a convenience sample of patients admitted with acute coronary syndrome. PCI was the preferred treatment for $80 \%$ of respondents but $83 \%$ of patients would accept "any treatment, no matter how extreme, to return their health to what it was."

Kipp et $\mathrm{al}^{9}$ hypothesized that patients would choose PCI over CABG even if quoted 1-year PCI risks were higher than those observed in the SYNTAX trial. CABG risk estimates remained fixed across all hypothetical risk scenarios, a 1-year risk of death, stroke, and need for a repeat procedure of $3 \%, 2 \%$, and $5 \%$, respectively, and the PCI risks was randomly generated between death $(2 \%, 4 \%$, or $6 \%$ ), stroke $(1 \%$ or $2 \%)$, and repeat procedures $(7 \%, 11 \%$, $15 \%$, or $17 \%$ ). Patients preferred PCI over CABG even if the risk of repeat procedure was three times higher and the risk of death was twofold the CABG risks. Although stroke presented a similar trend, the difference was not statistically significant.

\section{Discussion}

In this systematic review, we opted to include exclusively SP studies. The rationale for this decision can be broken down as follows: 1) the application of SP studies to elicit patient's preferences is becoming increasingly popular in the field of healthcare and medical decision-making, ${ }^{11}$ so we believe that this work contributes as a roadmap to the evidence that has been generated in regards to current patients preferences; 2) the idiosyncratic characteristics of SP experiments, as for instance the resort to experimental designs to generate paired comparisons, allows researchers to create "ideal conditions" (eg, orthogonality) to estimate the relative preference weight placed in different features of a healthcare intervention or treatment; and 3) furthermore, this type of experiment can be tailored to explore the importance placed in features that are not usually explicitly presented to and considered by healthcare consumers, patients and caregivers or, as shown 
in this review, to examine the relative importance of different classic cardiovascular endpoints that are usually reported together as composite outcomes in clinical studies.

SP studies are, at times, a target of criticism for using paired comparisons of hypothetical scenarios as an instrument to elicit preference weights. Some may argue that such hypothetical scenarios do not represent the choices that would be made in real life. ${ }^{4}$ The selection of stated rather than RPs in the evaluation of the trade-offs between PCI and CABG is justified since it is very unlikely that previous treatments could represent the choices that patients had made. Previous CABG or PCI does not mean that the patient had the opportunity to choose and had selected according to his or her own values.

The attributes identified in the selected studies represent the different aspects that should be considered when sharing the decision between PCI and CABG. According to utility theory, the best option would be represented by the one with the best combination of risks and benefits (and results in utility maximization). ${ }^{12}$ These attributes can be ranked in future trials according to different perspectives such as physicians, patients, caregivers or decision makers, and the selection of the attributes to be considered in composite endpoints should ideally take into consideration their relative weights. We ranked and rated 14 attributes with patients and physicians from a tertiary cardiologic hospital in Rio de Janeiro, Brazil and we identified a significant difference between their perspectives ${ }^{13}$ which is in agreement with the findings of the Pandit, ${ }^{6} \mathrm{Ahmad}^{8}$ and Kipp ${ }^{9}$ studies.

Interestingly, even though coronary disease is considered a health problem worldwide and there was no language limitation in our literature search, it was only possible to identify studies from the USA and UK. Another notable issue identified in this review was the variety of methods to evaluate the preferences, such as rating, ranking, standard gamble and discrete choice experiments, which highlight the absence of a gold standard method.

All these findings, associated with the low number of published studies and the total absence of studies funded by manufacturers and pharmaceutical companies, suggest that the interest in the knowledge of the preferences of patients has not yet reached its apex.

\section{Conclusion}

The guidelines recommendations on CAD treatments may be based on endpoints that do not represent patients' preferences properly. The development of knowledge on patients' preferences, values, and fears could inform policy and enable physicians to be more accountable to the public.

Current evidence on preferences between PCI and CABG is sparse and eliciting patients' preferences is fraught with methodological challenges. The preference studies in this systematic review included heterogeneous populations, different methods to elicit preferences and many distinct outcomes.

Despite these limitations, it was possible to identify many important attributes that may serve as the basis for scenario design in future SP studies and to conclude that different outcomes are valued differently by patients and physicians. Future trials should carefully consider if any relevant outcome was omitted, if the outcomes included are clinically meaningful and to weigh them appropriately according to patients' preferences.

\section{Acknowledgment}

There was no funding for this study.

\section{Disclosure}

The authors report no conflicts of interest in this work.

\section{References}

1. Serruys PW, Morice MC, Kappetein AP, et al. Percutaneous coronary intervention versus coronary-artery bypass grafting for severe coronary artery disease. $N$ Engl J Med. 2009;360(10):961-972.

2. Hornberger J, Bloch DA, Hlatky MA, Baumgartner W. Patient preferences in coronary revascularization. Am Heart J. 1999;137(6): 1153-1162.

3. Purnell TS, Joy S, Little E, Bridges JF, Maruthur N. Patient preferences for noninsulin diabetes medications: a systematic review. Diabetes Care. 2014;37(7):2055-2062.

4. Bridges JFP, Onukwugha E, Johnson R, Hauber AB. Patient Preference Methods: A Patient Centered Evaluation Paradigm. ISPOR Connections. 2007:13(6);4-7.

5. Liberati A, Altman DG, Tetzlaff J, et al. The PRISMA statement for reporting systematic reviews and meta-analyses of studies that evaluate health care interventions: explanation and elaboration. J Clin Epidemiol. 2009;62(10):e1-e34.

6. Pandit J, Gupta V, Boyer N, Yeghiazarians Y, Ports TA, Boyle AJ Patient and physician perspectives on outcomes weighting in revascularization. The POWR study. Int J Cardiol. 2014;177(2):513-514.

7. Chow RD, Wankhedkar KP, Mete M. Patients' preferences for selection of endpoints in cardiovascular clinical trials. J Commun Hosp Int Med Perspect. 2014;4(1):22643.

8. Ahmad Y, Nijjer S, Cook CM, et al. A new method of applying randomised control study data to the individual patient: a novel quantitative patient-centred approach to interpreting composite end points. Int $J$ Cardiol. 2015;195:216-224.

9. Kipp R, Lehman J, Israel J, Edwards N, Becker T, Raval AN. Patient preferences for coronary artery bypass graft surgery or percutaneous intervention in multivessel coronary artery disease. Catheter Cardiovasc Interv. 2013;82(2):212-218.

10. Bowling A, Culliford L, Smith D, Rowe G, Reeves BC. What do patients really want? Patients' preferences for treatment for angina. Health Expect. 2008;11(2):137-147. 
11. Soekhai V, de Bekker-Grob EW, Ellis AR, Vass CM. Discrete choice experiments in health economics: past, present and future. PharmacoEconomics. 2018;10(2):1-26.

12. Hellinger FJ. Expected utility theory and risky choices with health outcomes. Med Care. 1989;27(3):273-279.
13. Magliano C, Monteiro AL, Tura BR, Oliveira CSR, Rebelo ARO, Pereira CCA. Patient and physician preferences for attributes of coronary revascularization. Patient Prefer Adherence. 2018;12:757-764. 


\section{Supplementary material}

Table SI Full eletronic search strategy executed on Medline, Embase and Lilacs databases for studies regarding patients' preferences for coronary revascularization

\begin{tabular}{|c|c|}
\hline Database & Strategy \\
\hline Medline & 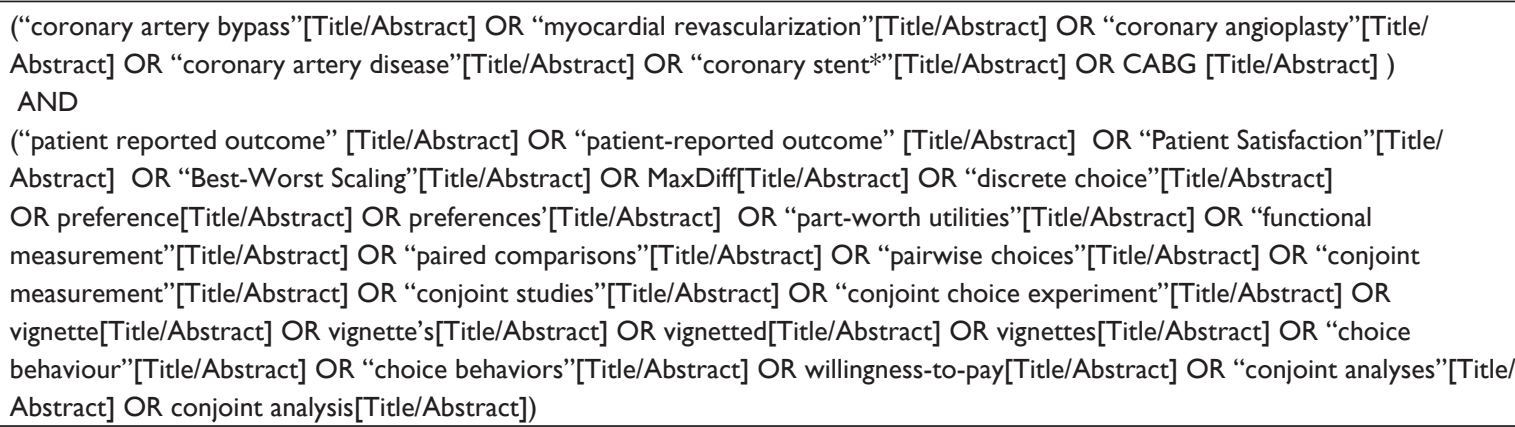 \\
\hline EMBASE & 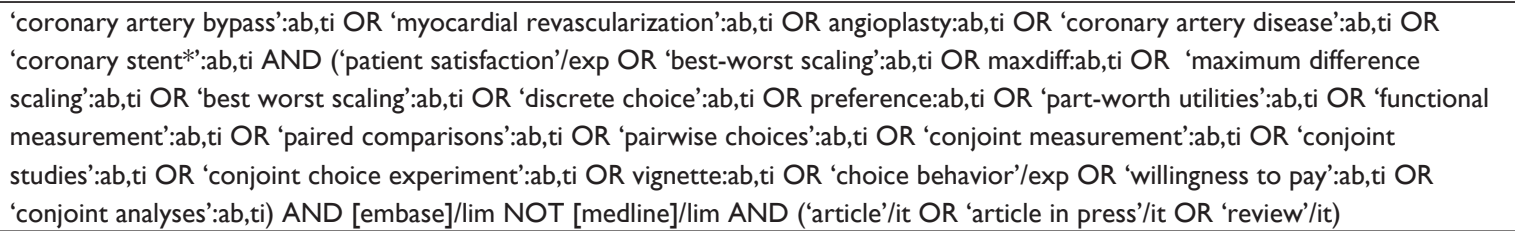 \\
\hline Lilacs & $\begin{array}{l}\text { ('best-worst scaling' OR maxdiff OR discrete choice OR ‘escolha discreta' OR preference OR preferencia OR 'part-worth } \\
\text { utilities' OR vignette OR 'choice behavior' OR 'willingness to pay') AND (angina OR angioplasty OR angioplastia OR myocardial } \\
\text { revascularization OR miocárdica OR coronary OR coronaria) }\end{array}$ \\
\hline
\end{tabular}

\section{Publish your work in this journal}

Patient Preference and Adherence is an international, peer-reviewed, open access journal that focuses on the growing importance of patient preference and adherence throughout the therapeutic continuum. Patient satisfaction, acceptability, quality of life, compliance, persistence and their role in developing new therapeutic modalities and compounds to optimize clinical outcomes for existing disease states are major areas of interest for the journal. This journal has been accepted for indexing on PubMed Central. The manuscript management system is completely online and includes a very quick and fair peer-review system, which is all easy to use. Visit http://www. dovepress.com/testimonials.php to read real quotes from published authors. 